\title{
Relato da utilização da plataforma App Inventor como ferramenta de ensino de lógica de programação para professores da Rede Básica de Ensino
}

\author{
Felício Gobbi Hoffmann Santos Pereira ${ }^{1}$, Graziela Santos de Araújo ${ }^{1}$, \\ Luciana Montera Cheung ${ }^{1}$ Anderson Viçoso de Araujo ${ }^{1}$, Heitor Batistela Zunta ${ }^{2}$ \\ ${ }^{1}$ Faculdade de Computação - Universidade Federal de Mato Grosso do Sul (UFMS) \\ Campo Grande - MS - Brasil
}

${ }^{2}$ Divisão de Tecnologia Educacional - Secretaria Municipal de Educação de Campo Grande Campo Grande - MS - Brasil

hoffmann.felicio@gmail.com, \{gsa, andvicoso\}@facom.ufms.br,
luciana.montera@ufms.br, heitor.zunta@icloud.com

\begin{abstract}
This paper reports the realization of a training with elementary school teachers aiming to teach the process of developing mobile applications. The chosen platform allows programming without the need to know programming logic concepts in advance. It is expected that teachers use new technologies in their school day-to-day and multiply the knowledge acquired, thus promoting digital culture in the classroom.
\end{abstract}

Resumo. Este artigo relata a realização de uma capacitação com professores de ensino fundamental, com o intuito de ensinar o processo de desenvolvimento de aplicativos móveis. A plataforma utilizada permite a programação sem a necessidade de conhecer previamente conceitos de lógica de programação. Espera-se que, com isso, os professores utilizem novas tecnologias no seu dia-adia na escola e sejam multiplicadores do conhecimento adquirido, promovendo assim a cultura digital em sala de aula.

\section{Introdução}

A Computação é uma área que permeia todas as demais áreas do conhecimento, não sendo mais possível imaginar uma sociedade na qual os indivíduos não necessitem de conhecimentos básicos de computação [Raabe et al. 2017]. A abrangência da Computação faz com que todas as pessoas, principalmente jovens e crianças em idade escolar, estejam cada vez mais imersos no mundo digital.

Novas formas de aprender e ensinar, fazendo uso de ferramentas de tecnologia da informação, mostram-se mais atrativas para a geração atual de jovens que aprendem explorando, tentando e desenvolvendo conhecimento. No entanto, na Educação Básica, a presença destas tecnologias é pouco significativa e seu potencial é ainda pouco explorado [de Almeida e Valente 2012].

Homologada pela Portaria número 1.570, de 20 de dezembro de 2017, a Base Nacional Comum Curricular (BNCC), conforme seu texto introdutório, é um documento normativo que define um conjunto de habilidades essenciais que devem ser desenvolvidas por todos os alunos, em todas as etapas e modalidades da Educação Básica. A BNCC integra 
a política nacional para a Educação Básica, é referência para a elaboração dos currículos dos sistemas e das redes estaduais, municipais e distrital, bem como da formação de professores, elaboração de conteúdos educacionais e avaliações [Vargas e Gonçalvez 2005].

"Utilizar tecnologias digitais de comunicação e informação de forma crítica, significativa, reflexiva e ética nas diversas práticas do cotidiano (incluindo as escolares) ao comunicar, acessar e disseminar informações, produzir conhecimento e resolver problemas."

Desenvolver a habilidade de resolução de problemas está intrinsecamente relacionada a compreender e utilizar o pensamento computacional como ferramenta para resolver problemas do dia-a-dia inerentes ao cotidiano das pessoas na sociedade.

O Pensamento Computacional, termo popularizado por Jeannette Wing, envolve a forma como resolvemos problemas e desenvolvemos sistemas [Wing 2006]. É o processo de reconhecer os aspectos computacionais no mundo, e aplicar ferramentas e técnicas da Ciência da Computação para compreender e raciocinar sobre os sistemas e processos naturais e artificiais, segundo [Bombasar et al. 2015]. Desenvolver o pensamento computacional nos alunos é um grande desafio para os professores em geral.

Ao utilizar as tecnologias como estratégia de ensino é preciso ter clareza de todos os fazeres pedagógicos. No projeto, no planejamento, no currículo, nas competências e habilidades que se quer desenvolver e no processo avaliativo. O grande desafio para uso da tecnologia no processos educacionais é a preparação dos docentes para essa prática no intuito de desenvolver as habilidades a partir de práticas pedagógicas inovadores, contemporâneas e significativas. Segundo [Gonçalves et al. 2018], a formação de professores é um dos pilares para a integração das TDICs ao currículo escolar. A formação visa que os docentes aprendam a consumir e entender a mecânica de produção da mesma, para adquirir segurança e construir gradativamente a cultura digital no âmbito da vida pessoal e profissional. Estabelecer uma conexão entre os conteúdos e a tecnologia disponível com intuito de alterar o papel de meros consumidores de tecnologia dos estudantes para pessoas criativas capazes de desenvolver estratégias e artefatos para resolução de problemas e o engajamento na produção de tecnologia de modo responsável.

Este artigo tem como objetivo relatar a experiência de capacitação oferecida a professores de ensino fundamental da Rede Municipal de Ensino da cidade de Campo Grande no Mato Grosso do Sul, na utilização da ferramenta App Inventor para o desenvolvimento de aplicativos móveis com o objetivo maior de serem multiplicadores do conhecimento nas escolas municipais, espalhando a formação tecnológica e difundindo a cultura digital. Tal experiência também permite a identificação de jovens talentos na área da computação.

App Inventor é uma ferramenta educacional de desenvolvimento de aplicativos para dispositivos móveis com o sistema operacional Android, desenvolvida pelo Massachusetts Institute of Technology (MIT $\left.{ }^{1}\right)$. Esta foi a ferramenta escolhida para ser utilizada no projeto por ser de utilização livre, possuir versão online, trabalhar com lógica de programação por meio da linguagem de programação em blocos. A programação em blocos é uma estratégia de programação que facilita o entendimento e aprendizado do seu utilizador por ser baseada nas ações de "arrastar" e "soltar". Este método diminui a neces-

\footnotetext{
${ }^{1}$ https://appinventor.mit.edu
} 
sidade de aprender sobre a sintaxe de uma certa linguagem de programação e direciona os esforços no entendimento da lógica de programação.

\section{Metodologia}

Ao planejar uma formação em lógica de programação, foi possível estimular nos professores o pensamento computacional para construção de aplicativos tendo como objetivo final da formação o desenvolvimento de habilidades voltadas à criação de aplicativos pedagógicos a serem utilizados em sala de aula, bem como capacitar o professor para a utilização do software App Inventor como ferramenta meio em suas aulas, despertando assim seus alunos para a área de tecnologia da informação.

A formação deu-se em duas etapas, envolvendo vinte e oito professores de diversas áreas do conhecimento da rede municipal de ensino de Campo Grande - MS. A primeira delas foi constituída de cinco aulas presenciais,com duração de quatro horas cada, em um dos laboratórios de informática da Faculdade de Computação da Universidade Federal de Mato Grosso do Sul. Durantes as aulas, eram apresentadas aos participantes diferentes situações problemas do tipo "Como construir um aplicativo capaz de realizar a tradução de palavras escritas em português para o inglês e outras línguas?", "Como fazer um aplicativo capaz de ler um texto digitado pelo usuário?", "Como fazer um aplicativo que simule uma folha de papel onde é possível escrever e desenhar?", entre diversas outras situações. Uma vez entendido o problema, tais aplicativos eram instalados pelos alunos em seus dispositivos móveis para que estes pudessem ser usuários dos mesmos, antes de serem desenvolvedores.

Todas as situações problemas apresentadas se tornavam tarefas a serem implementadas. Para a implementação, os ministrantes das aulas apresentavam os componentes do software App Inventor necessárias para a implementação do aplicativo alvo. Por fim, o aplicativo era construído de forma conjunta pelos ministrantes e participantes. Após o término do aplicativo, o ministrante apresentava um ou mais desafios aos participantes, que eram motivados a implementar uma funcionalidade diferente/adicional capaz de potencializar o aplicativo desenvolvido. Por vezes, os participantes utilizaram do tempo restante da aula presencial para implementar suas soluções para os desafios, realizando consultas aos materiais das aulas anteriores, buscas nos materiais adicionais utilizados como referência, ou ainda, interagindo com os ministrantes e com seus colegas de turma. O momento dedicado a esta atividade mostrou-se de extrema importância para a fixação dos conhecimentos adquiridos durante as aulas, bem como para colocar o participante no papel de protagonista da ação de busca pelo conhecimento.

Seguindo a metodologia descrita anteriormente, foi possível apresentar diversas ferramentas e componentes comumente utilizados no desenvolvimento de aplicativos pela ferramenta App Inventor, tais como legendas, botões, caixas de texto, sensores, som, dentre outros. O desenvolvimento deu-se primeiramente pela criação da interface do aplicativo, seguida da programação dos componentes presentes na interface. Neste último momento, trabalhou-se a lógica de programação e a programação baseada em blocos. Em cada aula presencial, três tarefas foram desenvolvidas em média, além de algumas variações destas. Os materiais das tarefas estão disponíveis no site do projeto ${ }^{2}$. A última aula presencial foi realizada a fim de preparar o aluno para a etapa seguinte de trabalho,

\footnotetext{
${ }^{2}$ www.destacom.ufms.br
} 
realizada à distância. Nesta etapa os alunos, em pares ou individualmente, trabalharam no desenvolvimento de um aplicativo para atender a uma demanda específica e de livre escolha. Os ministrantes apresentaram de forma sucinta etapas a serem seguidas para o desenvolvimento de uma aplicação, dentre elas: definição do objetivo do aplicativo, definição do público alvo do aplicativo, busca e análise de aplicativos semelhantes, projeto de layout do aplicativo e programação do aplicativo.

A segunda etapa consistiu no momento avaliativo, no qual os cursistas tiveram um período de três semanas para desenvolverem um aplicativo utilizando os conceitos e conhecimentos abordados na etapa anterior. As duas primeiras semanas foram destinadas à elaboração do programa e codificação. Ela contou com o auxílio dos ministrantes e colaboradores do curso por meio de ferramentas de mensagens e dois encontros presenciais, nos quais foram realizados momentos individuais para esclarecimento de dúvidas específicas de cada grupo na criação do aplicativo. Na última semana o projeto fora submetido à avaliação e culminou em apresentação e contribuições pedagógicas pelos professores da FACOM.

\section{Resultados}

Houve grande diversidade dentre os aplicativos construídos. Entretanto, a maioria abordou assuntos tratados pelos professores em suas disciplinas ministradas na Rede Municipal de Ensino.

Dentre as diversas aplicações desenvolvidas pelos participantes do curso, destacamos a aplicação Controlador de Luz, por ser a única aplicação onde houve a integração entre o App Inventor e uma placa de Arduíno com três LEDs. A Figura 1 apresenta a tela do aplicativo e um trecho do seu código. O aplicativo apresenta como é possível, via Bluetooth, que luzes se apaguem ou se acendam. Na construção foram utilizadas paletas da Interface de Usuário, Organização e Conectividade. Alguns componentes utilizados nesta aplicação não foram utilizados em nenhuma das tarefas vistas nas aulas ministradas.



Figura 1. Tela principal e trecho do código da aplicação Controlador de Luz que controla o acender e o apagar de luzes de LED em uma placa Arduíno. 


\section{Considerações finais}

Durante o encontro para a apresentação dos projetos, os professores participantes do curso puderam apresentar suas motivações para a escolha da temática abordada, bem como suas dificuldades durante o desenvolvimento do aplicativo. Foram realizados também relatos da utilização de alguns aplicativos em sala de aula. Os alunos da rede municipal, que tiveram acesso a elas, receberam a novidade de forma muito positiva, relatando ser mais divertido aprender utilizando o dispositivo móvel em sala de aula e que seria também mais interessante estudar em casa, sobretudo pelo fato do aplicativo ter sido desenvolvido pelo seu professor.

Alguns professores relataram ainda que o aprendizado dessa nova tecnologia não foi tão complexo quanto pressuposto inicialmente. Também houveram relatos sobre continuar utilizando e estudando a ferramenta App Inventor a fim de desenvolver novos aplicativos para suas aulas. Durante os encontros, novas ideias foram compartilhadas entre os presentes e podem direcionar o desenvolvimento de novas ferramentas.

Acreditamos que a metodologia utilizada resultou em uma formação sólida e atendeu aos propósitos da equipe que idealizou e realizou o curso, sobretudo no período de trabalho à distância, pois os participantes puderam experimentar as potencialidades do App Inventor de forma autônoma e certamente fez com que despertasse ainda mais o interesse pela sua utilização, uma vez que cada participante teve a oportunidade de desenvolver uma solução para um problema presente na sua rotina de trabalho.

\section{Agradecimentos}

O presente trabalho foi realizado com apoio da Universidade Federal de Mato Grosso do Sul - UFMS/MEC - Brasil.

\section{Referências}

Bombasar, J., Raabe, A., Miranda, E., e Santiago, R. (2015). Ferramentas para o ensinoaprendizagem do pensamento computacional: onde está alan turing? Brazilian Symposium on Computers in Education (Simpósio Brasileiro de Informática na Educação - SBIE), 26(1).

de Almeida, M. E. B. e Valente, J. A. (2012). Integração currículo e tecnologias e a produção de narrativas digitais. Currículo sem fronteiras, 12(3):57-82.

Gonçalves, L. M., Perrier, G. R. F., e Almeida, M. E. B. (2018). Avanços, entraves e possibilidades de integração curricular das tdic: as representações sociais de professores do ensino fundamental i. Cadernos de Educação, I(60):50-74.

Raabe, A., Frango, I., Ribeiro, L., Granville, L., Salgado, L., da Cruz, M., e Fortes, S. (2017). Referenciais de formação em computação: Educação básica. Sociedade Brasileira de Computação.

Vargas, R. e Gonçalvez, A. (2005). Implementando um Mural Eletrônico em PHP: Uma Aplicação Voltada a uma Instituição de Ensino Superior. Monografia (Bacharel em Informática), URCAMP (Universidade da Região da Campanha), Bagé, Brazil.

Wing, J. M. (2006). Computational thinking. Commun. ACM, 49(3):33-35. 